\title{
AN INTEGRATED MAXIMUM POWER POINT TRACKING TECHNIQUE FOR SOLAR INVERTERS WITH BATTERY STORAGE
}

\author{
${ }^{1}$ T. K.CHINNASUBBARAYUDU, ${ }^{2} \mathrm{M}$. BALA SIVA PRASAD \\ ${ }^{1}$ pg Student, Dept Of Electrical And Electronics Engineering, Annamacharya Institute Of Technology \& Sciences, \\ Rajampaeta, Kadapa (D), India \\ ${ }^{2}$ assistant Professor, Dept Of Electrical And Electronics Engineering, Annamacharya Institute Of Technology \& Sciences, \\ Rajampaeta, Kadapa (D), India \\ Email ID: subbarayudu805@gmail.com, balasivaprasad@gmail.com
}

\begin{abstract}
This project propose an approach of synchronized and included supervision of solar power PV turbines with the maximum power point tracking (MPPT) supervision and battery power program storage space supervision to offer voltage and frequency (V-f) support to an islanded micro grid. Also, resourceful and active/reactive power (P-Q) supervision with solar power PV, MPPT and battery power pack program energy program storage space area is suggested for the lines connected mode. The results clearly confirm the potency of suggested supervision methods. The models are carried out in Matlab and Sim power systems.
\end{abstract}

\section{INTRODUCTION}

The micro grid is a selection of allocated turbines or micro resources, energy space for storage gadgets, and loads which function as a single and separate manageable system capable of offering both energy and potential to the area of service. The micro resources that are incorporated in a micro grid are consists of small models, less than $100 \mathrm{~kW}$, offered with power electronic (PE) interface. Most common sources are solar power Photovoltaic or pv (PV), Fuel Cell (FC), or micro turbines linked at the distribution voltage level.

A dynamic voltage regulation based on adaptive supervision is proposed. However, there are not many research works performed on $\mathrm{V}-\mathrm{f}$ or $\mathrm{P}-\mathrm{Q}$ supervision using solar PV including MPPT supervision and battery power storage in micro grids. The voltage and frequency control with solar PV and battery power in micro grid with an induction machine is investigated; however, this work does not explain the transfer mechanism of controls to consider battery power SOC constraint.

This is a very essential contribution from this perform as in comparison to other literatures in this place. At the same time, the control can easily convert from one method e.g., inverter P-Q supervision e.g., inverter $\mathrm{P}-\mathrm{Q}$ control in grid connected mode to V-f control in islanded mode. The suggested control techniques are verified with acceptable outcomes.

\section{SOLAR PV MODELING AND VALIDATION}

The commonly accepted solar panel design is a one diode design. This work uses the single diode design of the solar panel to design the Kyocera KC200GT solar array, which is shown in Fig. 1.

The I-V characteristics of a solar array, as shown in Fig. 2, are represented by (1).

$$
I=I_{\mathrm{PV}}-I_{0}\left[\exp \left(\frac{V+R_{s} I}{V_{\text {therm }} a}\right)-1\right]-\frac{V+R_{s} I}{R_{\mathrm{sh}}}
$$

where $I_{\mathrm{PV}}$ and $I_{o \text { }}$ are the photo current and the diode saturation currents, respectively $V_{\text {therm }}\left(=N_{s} k T / q\right)$ is the thermal voltage of the array, $N_{s}$ being the cells connected in series for greater output voltage, $k$ is the Boltzmann constant $\left.1.3806503 \times 10^{-23} \mathrm{~J} / \mathrm{K}\right), \mathrm{T}$ (Kelvin) is the temperature of the $\mathrm{p}-\mathrm{n}$ junction of the diode, and $q\left(1.60217646 \times 10^{-19} \mathrm{C}\right)$ is the electron charge; Rs and Rsh are the equivalent series and shunt resistances of the array, respectively; and a is the ideality factor usually chosen in the range $1 \leq a \leq 1.5$. Here a is taken as 1 .

The photocurrent of the PV range relies upon linearly on the solar power irradiance and the mobile heat range, as proven by (2).

$$
I_{\mathrm{PV}}=\left(I_{\mathrm{PV}, n}+K_{1} \Delta T\right) \frac{G}{G_{n}}
$$

where $I_{\mathrm{PV}, n}$ is the photocurrent at the typical test condition (STC, $25 \mathrm{C}$ and $1000 \mathrm{~W} / \mathrm{m} 2) ; K_{I}$ is the short circuit current/ temperature co resourceful ; $\Delta T^{\prime}$ is the difference between the actual and ostensible temperature in Kelvin; $G$ is the remission on the device outside; and $G_{n}$ is the nominal emission, both in $\mathrm{W} / \mathrm{m}$.

can be calculated based on (3)

$$
I_{\mathrm{PV}, n}=\frac{R_{\mathrm{sh}}+R_{s}}{R_{\mathrm{sh}}} I_{\mathrm{sc}}
$$

Using these essential equations and factors from the information part, the PV design is designed and confirmed with the board datasheet. The I-V features of KC200GT for different irradiance stages at the mobile heat range of $25 \mathrm{C}$ and different mobile heat range for a constant irradiance stage of 1000 $\mathrm{W} / \mathrm{m}$ as acquired from the simulator are proven in 
Figs. 2(a) and (b), respectively. The resemblances of the I-V shapes for different conditions with the corresponding shapes in the KC200GT board datasheet confirm the reliability of the designed screen design. The factors of the PV board under research are proven in Table I.

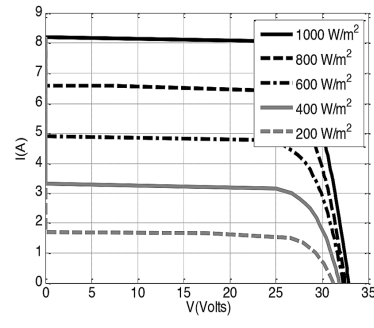

a)

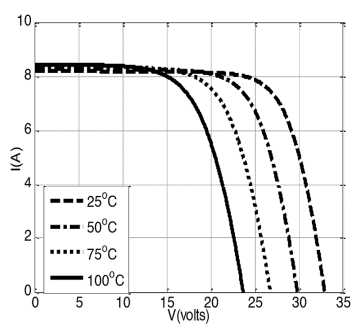

Fig. 2. The - characteristics of Kyocera KC200GT from simulation with (a) varying irradiance at a cell temperature of $25 \mathrm{C}$ and; (b) varying cell temperature at $1000 \mathrm{~W} / \mathrm{m}$.

TABLE I

PV PANEL PARAMETERS AT 1000 W/M AND 25

\begin{tabular}{|c|c|}
\hline \multicolumn{2}{|c|}{ C } \\
\hline Model & Kyocera KC200GT \\
\hline $\mathrm{P}_{\mathrm{MPP}}$ & $200 \mathrm{~W}$ \\
\hline $\mathrm{V}_{\mathrm{MPP}}$ & $26.30 \mathrm{~V}$ \\
\hline $\mathrm{I}_{\mathrm{MPP}}$ & $7.61 \mathrm{~A}$ \\
\hline $\mathrm{V}_{\mathrm{OC}}$ & $32.90 \mathrm{~V}$ \\
\hline $\mathrm{I}_{\mathrm{SC}}$ & $8.21 \mathrm{~A}$ \\
\hline
\end{tabular}

\section{PV SYSTEM CONFIGURATION AND SYSTEM DESCRIPTION}

\section{A. PV System Configuration}

Fig. 3 shows the PV program settings for V$\mathrm{f}$ and P-Q control with PV working at MPP such as battery power storage endorsement. It is a two-stage setting where a DC-DC boost converter is used for MPPT control.

The PV program is linked with the lines through a combining inductor Lc. The combining inductor filtration out the ripples in the PV output present. The relationship factor is known as the point of common coupling (PCC) and the PCC voltage is denoted as $\mathrm{Vt}(\mathrm{t})$. The rest of the programs in Fig. 3 signify the IEEE 13-bus submission distribution feeder which is simple as a substation with the distribution relative impedance, $R+j w L s$. The facts of the IEEE-13 bus program will be described in the next area. The PV resource is linked with the DC link of the inverter with a capacitor Cdc.

The average power of the PV denoted as $P(t)_{\star}$, the apparent power $S(t)$ and the average reactive power $Q(t)$ of the PV are as given below

$$
\begin{aligned}
& P(t)=\frac{2}{T} \int_{t-\frac{T}{2}}^{t} v_{t}(\tau) i_{c}(\tau) d \tau=\frac{V_{t}(t) V_{c}(t)}{\omega L_{c}} \sin \alpha \\
& S(t)=V_{t}(t) I_{c}(t)=\frac{v_{t}(t)}{\omega L_{c}} \sqrt{V_{t}(t)^{2}+V_{c}(t)^{2}-2 V_{t}(t) V_{c}(t) \cos \alpha} \\
& 2(t)=\sqrt{S^{2}(t)-P^{2}(t)}=\frac{V_{t}(t)}{\omega L_{c}}\left(V_{c}(t) \cos \alpha-V_{t}(t)\right)
\end{aligned}
$$

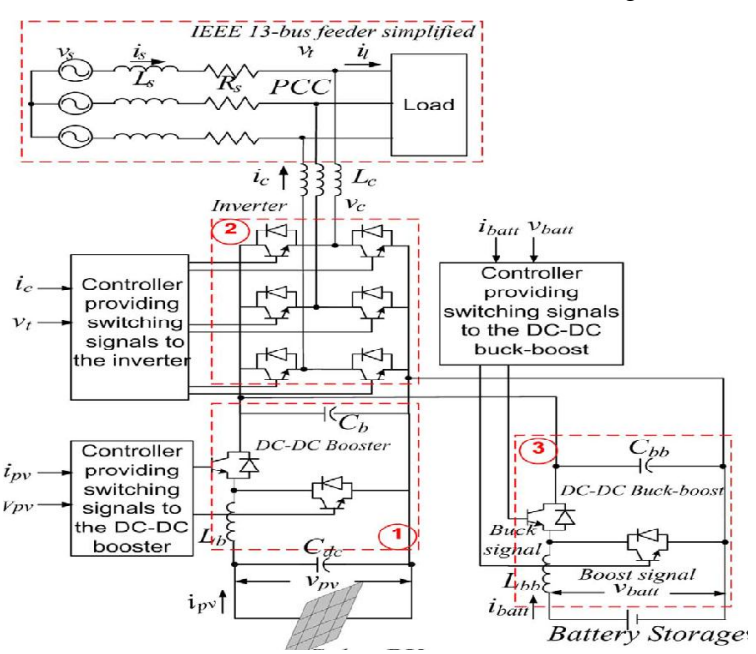

Fig. 3. System configuration of V-f control with solar PV generator operating at MPPT with a battery storage system.

Here, $\alpha$ is the phase angle of $\left.v_{c}(t)\right|_{\text {relative }}$ to the PCC voltage. $P(t)$ and $Q(t)$ in (4) and (6) can be approximated by the first terms of the Taylor series if the angle $\alpha$ is small, as shown in (7) and (8):

$$
\begin{aligned}
& P(t) \approx \frac{V_{t}(t) V_{c}(t)}{\omega L_{c}} \alpha \\
& Q(t) \approx \frac{V_{t}(t)}{\omega L_{c}}\left(V_{t}(t)-V_{c}(t)\right)
\end{aligned}
$$

\section{B. Battery Modeling}

In this document, battery power model is taken from the MATLAB Sim Power Systems library with appropriate factors which will be used for the proposed V-f and P-Q controls. Hence, in this document, a battery is modeled as a lead acid battery with appropriate choice of factors for deep cycle application. It is assumed that the cause acidity battery power can be discharged up to SOC of $20 \%$ and can be charged up to SOC of $80 \%$.

Battery energy pack design is an logical design with two equations representing battery energy discharge and charge models. Battery energy pack discharge and charge design for lead acid battery energy is given by (9) and (10), respectively

$$
\begin{aligned}
V_{\text {Batt }}= & V_{0}-R \cdot i-K \frac{Q}{Q-\mathrm{it}}\left(\mathrm{it}+t^{*}\right)+\operatorname{Exp}(t) \\
V_{\text {Batt }}= & V_{0}-R \cdot i-\left[K \frac{Q}{\mathrm{it}-0.1 Q}\right] i^{*}-\left[K \frac{Q}{Q-\mathrm{it}}\right] \cdot \mathrm{it} \\
& +\operatorname{Exp}(t)
\end{aligned}
$$

In this design, the phrase for polarization voltage and polarization level of resistance is considered to design the Open Circuit Voltage (OCV) of battery power more perfectly.

\section{Description of IEEE 13-Bus Distribution} Feeder

The plan of the IEEE 13-bus obedience analyze program is proven in Fig. 4. It includes a substation, 13 buses or nodes, 11 line segments, and 8 loads. The load consist of a grouping of constant 
impedance, constant current, and constant power (ZIP) loads but most of them are constant power loads. The substation is at $115 \mathrm{kV}$ and it is stepped down to $4.16 \mathrm{kV}$ by a distribution transformer (T1). There is one more transformer (T2) which steps down $4.16 \mathrm{kV}$ to $480 \mathrm{~V}$.

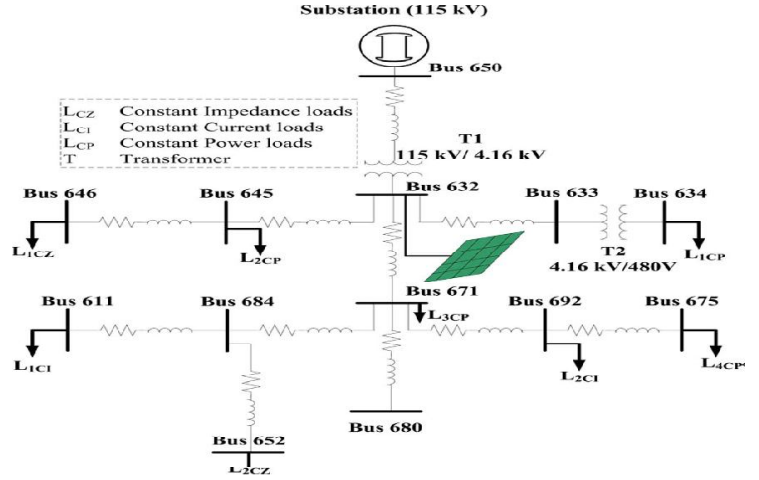

Fig. 4. IEEE-13 bus distribution feeder.

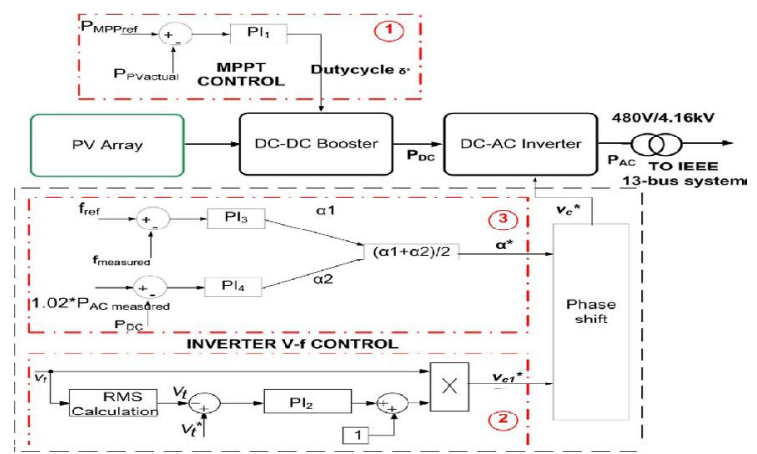

Fig. 5. Incorporated Solar PV MPPT and V-f control diagram.

\section{MPPT AND BATTERY INCORPORATED V-F AND P-Q CONTROL METHODS}

\section{A. MPPT and Battery Incorporated V-f Control Method}

The MPPT and battery power incorporated V-f control schemes are proven in Figs. 5 and 6, respectively. The control consists of one cycle for MPPT control, two different loops for V-f control at the inverter side and another cycle for battery power pack control.

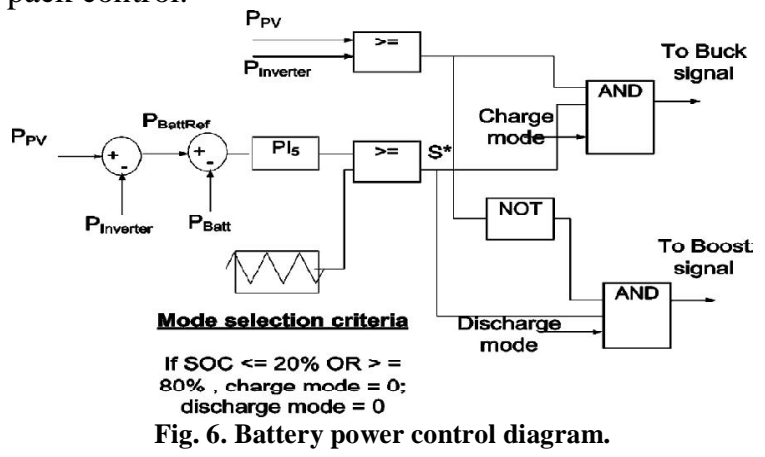

The equation for this control loop is given by (11). Here, $\mathrm{K}_{\mathrm{p} 1 \text { and }} \mathrm{K}_{\mathrm{i} 1}$ are the controller proportional and integral gains respectively
$\delta^{*}=K_{p 1} *\left(P_{\mathrm{MPP} \text { ref }}-P_{\mathrm{PV}}\right)+K_{i 1} * \int_{0}^{t}\left(P_{\mathrm{MPPref}}-P_{\mathrm{PV}}\right) d t$.

Another reviews PI controller PI2 is used for volts supervision at $\mathrm{AC}$ part. As proven in the supervision plan in Fig. 5 (loop2), the PCC volts is calculated and the rms value of $\mathrm{Vt}(\mathrm{t})$ is calculated. Then, the rms value $\mathrm{Vt}(\mathrm{t})$ is in comparison to a voltage reference $\mathrm{Vt}^{*}(\mathrm{t})$ which could be a voltage specified by the application, and the error is fed to a PI controller. The inverter outcome voltage $\mathrm{Vc}(\mathrm{t})$ is managed so that it is in stage with the PCC volts, and the scale of the inverter outcome volts is managed so that the PCC volts is controlled at a given stage $\mathrm{Vt}^{*}(\mathrm{t})$. The supervision plan can be particularly indicated as (12).

$$
\begin{aligned}
n_{\mathrm{c} 1}^{*}\left(t_{t}\right)=v_{t}\left(t_{t}\right)\left[1+K_{P 2}\left(V_{i}^{*}(t)-V_{t}(t)\right)\right. \\
\left.+K_{I 2} \int_{0}^{t}\left(\left(V_{t}^{*}(t)-V_{t}(t)\right) d t\right)\right]
\end{aligned}
$$

The frequency supervision is performed by managing the resourceful energy outcome at the inverter part as proven in the exterior loop 3. The optional microgrid frequency of $60 \mathrm{~Hz}$ is in contrast to the calculated value and this error is fed to the PI controller PI3 that provides the stage move contribution alpha*1 which changes the voltage waveform in timescale such that the resourceful energy treated will be enough to sustain the regularity at $60 \mathrm{~Hz}$ affordable value. The formula for this supervision is given by (13)

$$
\alpha_{1}^{*}=K_{P 3}\left(f_{\text {ref }}-f_{\text {measured }}\right)+K_{I 3} \int_{0}^{t}\left(f_{\text {ref }}-f_{\text {measured }}\right) d t
$$

There is another controller PI4 used in the same cycle 3. This controller conserve resourceful energy constancy between the AC and DC ends of the inverter. The referrals indication for PI4 is acquired from the enthusiastically modifying resourceful active power injection from the inverter at the $\mathrm{AC}$ part as identified by the outcome of PI3. The DC part resourceful energy is in contrast to this value of $\mathrm{AC}$ part energy and the error is fed to PI4 to acquire the stage move contribution from this cycle as alpha*2. The formula for this supervision is given by

$$
\begin{aligned}
\alpha_{2}^{*}=K_{P 4}\left(1.02 * P_{\mathrm{AC}}-P_{\mathrm{DC}}\right) & \\
& +K_{I 4} \int_{0}^{t}\left(1.02 * P_{\mathrm{AC}}-P_{\mathrm{DC}}\right) d t .
\end{aligned}
$$

The level move initiatives from DC and AC ends, alpha* 1 and alpha*2 are then averaged as given by (15) to acquire the final stage move, alpha* of the volts waveform, $\mathrm{Vc}^{*}$ which, then, produces the volts referrals indication $\mathrm{Vc}^{*}$ for the inverter PWM

$$
\alpha^{*}=\left(\alpha_{1}^{*}+\alpha_{2}^{*}\right) / 2 .
$$

Here, the reason behind considering stage move efforts from both DC and AC part resourceful 
energy is to supervision the DC part volts and accomplishes the preferred value. By making alpha*1 and alpha*2 close in variety through the controller benefits, it can rest confident that the resourceful energy at the DC and AC ends is healthy. This, along with the volts supervision cycle, guarantees that the DC part volts are managed at the value preferred by the AC part volts.

The controller consists of a PI controller, PI5 which gets the error indication acquired after subtracting the actual battery power pack, Pbatt from battery power referrals, Pbattref. The indication acquired from PI5 is then compared with a triangular waveform of unity scale to generate the indication, $\mathrm{S}^{*}$. This is similar to common pulse width Modulation (PWM) in inverter manages. Kp5 and Ki5 are the balanced and important benefits respectively. The formula for this control is given by (16)

$$
S^{*}=K_{P 5}\left(P_{\text {Battref }}-P_{\text {Batt }}\right)+K_{15} \int_{0}^{t}\left(P_{\text {Battref }}-P_{\text {Batt }}\right) d t .
$$

Hence, with this control analysis, the battery is capable of working in both guidelines and therefore, successfully asking for and discharging battery power whenever required. This will be confirmed through the results provided in Area VI of this project.

\section{B. Modification of V-F Control with Battery SOC Constraint}

When there is numerous solar power irradiance available and the resourceful energy needed for the micro grid regularity supervision is less than resourceful energy created by the PV creator at MPP i.e., Pfcontrol < Ppvmpp and simultaneously battery power SOC is $80 \%$, then, battery power cannot be billed beyond this maximum of SOC. In such situation, reducing the outcome energy of PV creator would cause to underutilization of the solar power source.

Figs. 6, 7, and 8 show the variations of manage at different levels in the micro grid in order to deal with the above situations. Fig. 7 reveals the conversion of the diesel fuel generator supervision from constant active power control to frequency. Instead of considering the error between the referrals electric energy and the calculated electric energy to generate the technical energy referrals, the regularity error is considered in the controls. Fig. 8 reveals the advance in regularity supervision cycle of the PV inverter which includes the conversion to another constant resourceful energy supervision cycle. During the simulator process, the conversion time is heuristically selected as $8 \mathrm{sec}$ so that the in the transfer of controls can be noticed.

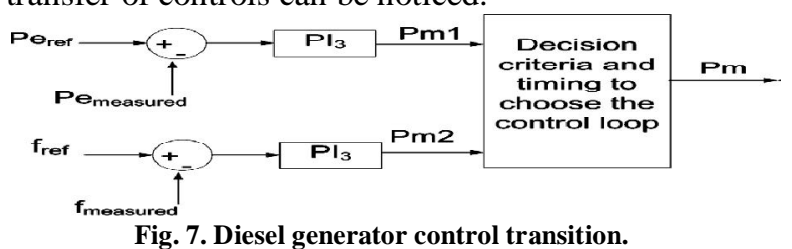

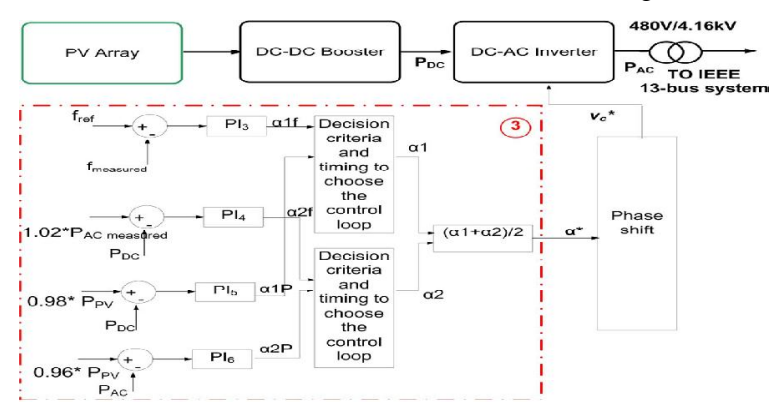

Fig. 8. Modification of PV inverter frequency control loop.

The slight modification required in battery power control for taking care of battery power SOC is also shown in Fig. 6. It includes integration of a signal for selecting the cost or discharge method of battery power. When the SOC $>80 \%$ or SOC $<20 \%$, then, both the cost and discharge mode are given the value of 0 such that the output is always zero for these two cases. In other cases, the cost method would take a value of 1 and the discharge method would take a value of 0 if battery power is charging, and vice versa if battery power is discharging.

\section{MPPT and Battery Incorporated P-Q Control Method}

This sub-section provides the suggested synchronized resourceful and non-active/reactive ( $\mathrm{P}$ Q) power supervision included with PV MPPT and battery power manages. Either in lines linked or islanded method, the micro resources may be required to supply crucial loads like medical centers, sectors, etc. Thus, Fig. 9 reveals the P-Q supervision prevents only, making behind the MPPT supervision prevent which also exists in the entire included supervision program. The P-Q supervision originally suggested and applied in a larger system is transformed to a more resourceful supervision with the integration of MPPT supervision and battery power storage supervision in the existing work.

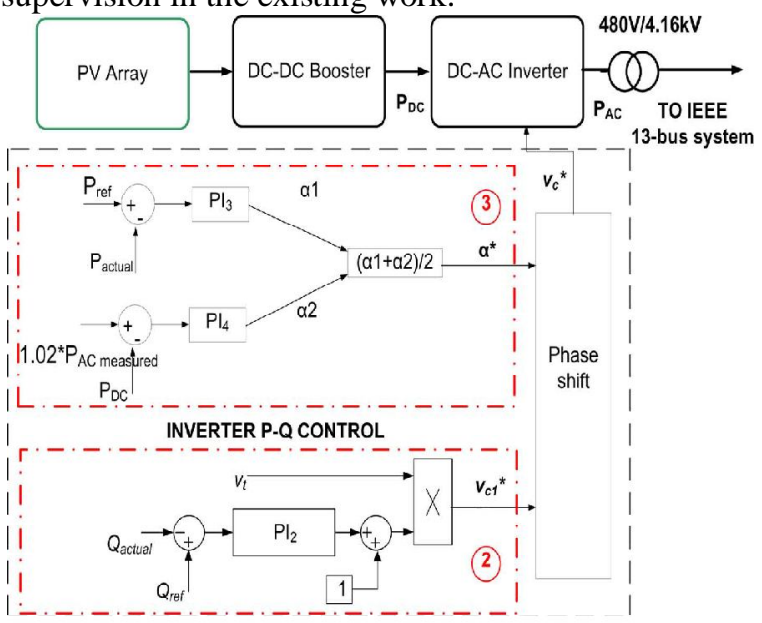

Fig. 9. Incorporated Solar PV MPPT and PQ control diagram.

The inverter part P-Q supervision is a little bit personalized edition of inverter $\mathrm{V}-\mathrm{f}$ control. It is entirely in accordance with the connection of resourceful and sensitive energy at PCC with inverter outcome stage and volts scale as given by the 
(7) and (8), respectively. Thus, the equations for P-Q supervision are given by (17)-(20)

$$
\begin{aligned}
v_{c 1}^{*}= & \left(K_{P 2}\left(Q_{\text {ref }}-Q_{\text {actual }}\right)\right. \\
& \left.+K_{I 2} \int_{0}^{t}\left(Q_{\text {ref }}-Q_{\text {actual }}\right) d t+1\right) v_{t} \\
\alpha_{1}^{*}= & K_{P 3}\left(P_{\text {ref }}-P_{\text {actual }}\right) \\
& +K_{I 3} \int_{0}^{t}\left(P_{\text {ref }}-P_{\text {actual }}\right) d t \\
\alpha_{2}^{*}= & K_{P 4}\left(1.02 * P_{\text {ACmeasured }}-P_{\mathrm{DC}}\right) \\
& +K_{14} \int_{0}^{t}\left(1.02 * P_{\text {ACmeasured }}-P_{\mathrm{DC}}\right) d t \\
\alpha^{*}= & \left(\alpha_{1}^{*}+\alpha_{2}^{*}\right) / 2
\end{aligned}
$$

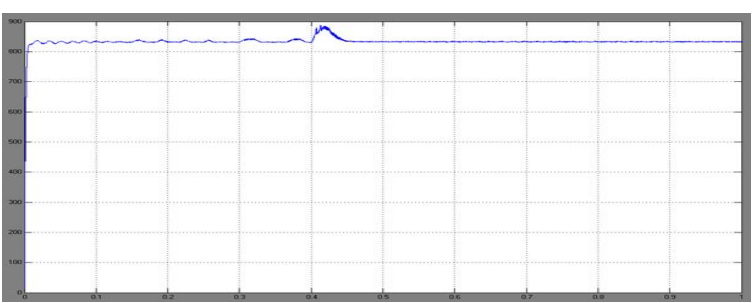

e) Vdc Voltage

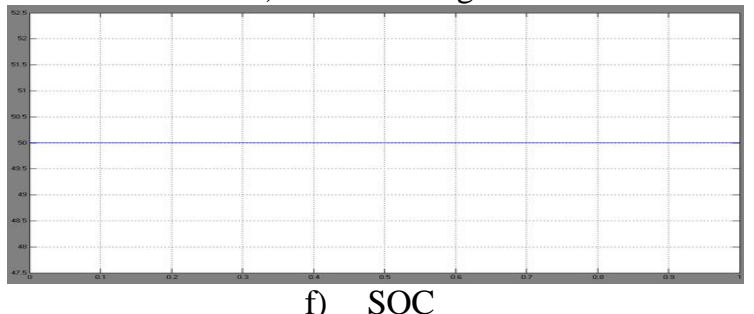
contribution obtained from the resourceful energy supervision at the $\mathrm{AC}$ and $\mathrm{DC}$ ends such that the resourceful energy supervision at $\mathrm{AC}$ side and power reliability objectives are taken into account.

\section{SIMULATION RESULTS}

1. Results of synchronized V-f control with solar PV including MPPT control and battery control

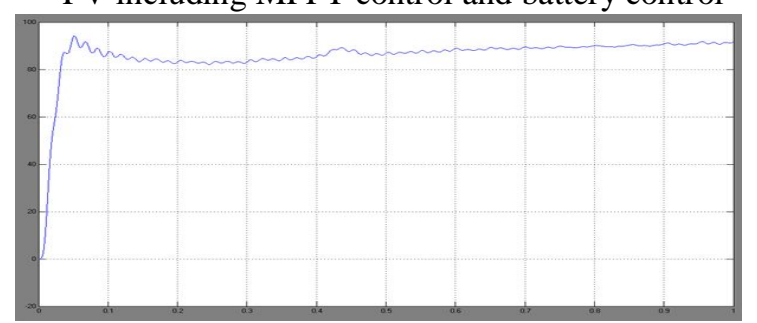

a) Inverter Active Power

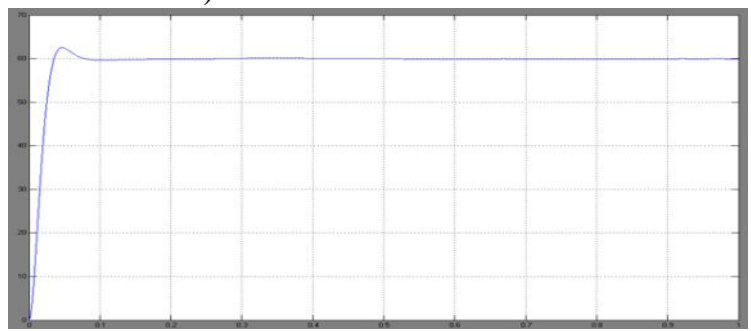

b) Frequency

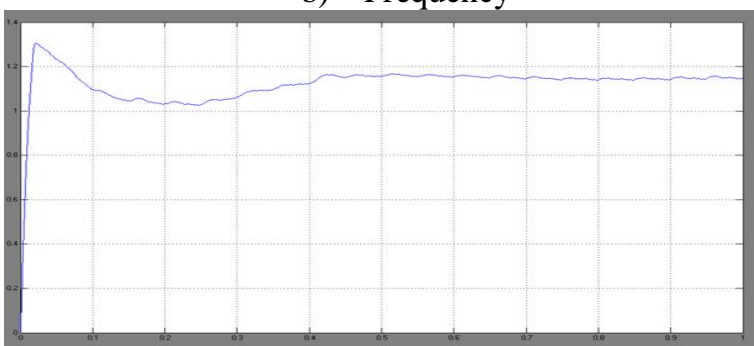

c) Voltage $(\mathrm{pu})$

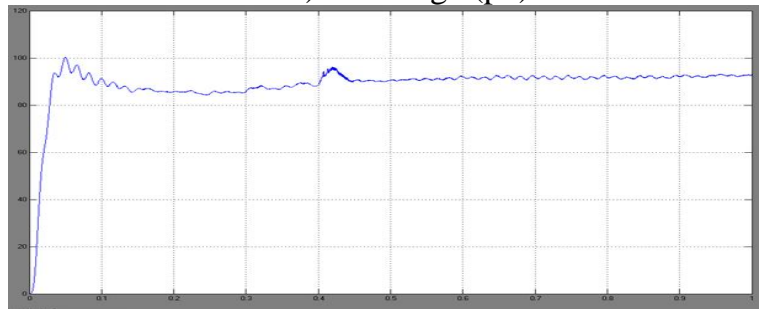

d) Pdc Active Power

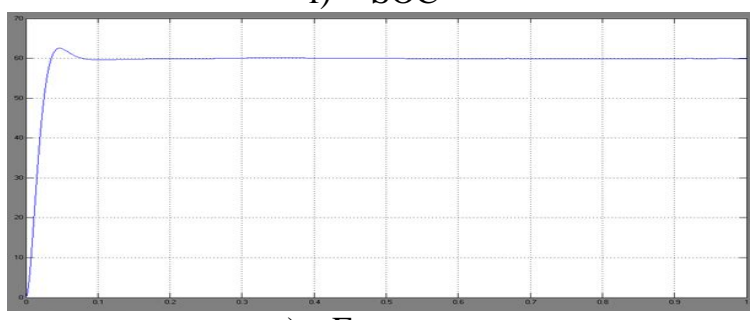

g) Frequency

2. Results of synchronized P-Q control with solar PV including MPPT control and battery control

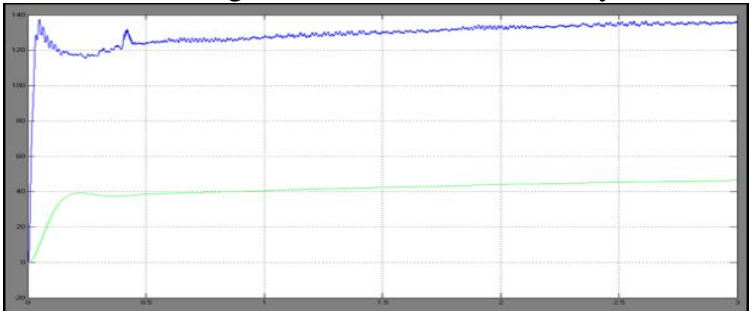

a) Inverter Active Power and Reactive Power

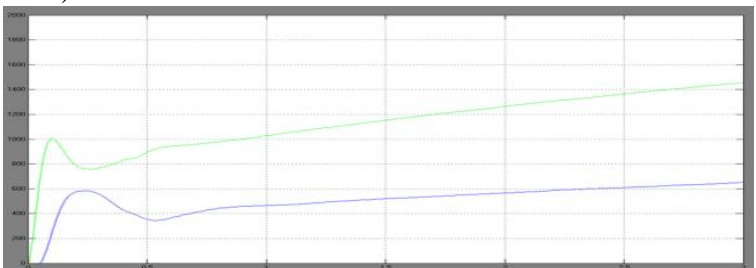

b) Active Power and Reactive Power of the Generator

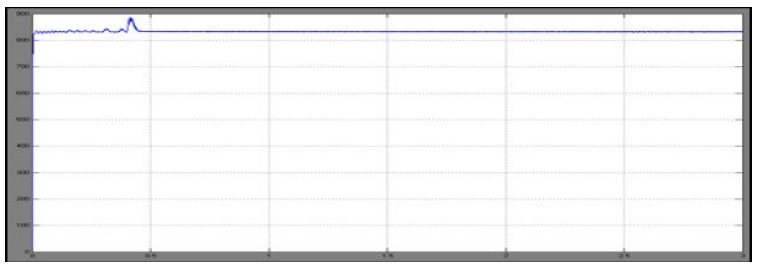

c) DC Voltage

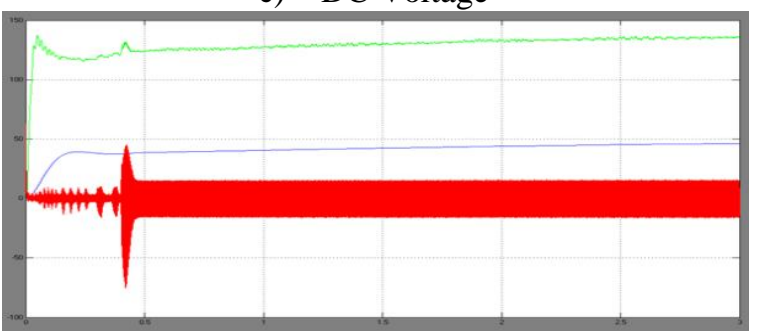

An Integrated Maximum Power Point Tracking Technique For Solar Inverters With Battery Storage 
Active power of an inverter,pv \& battery

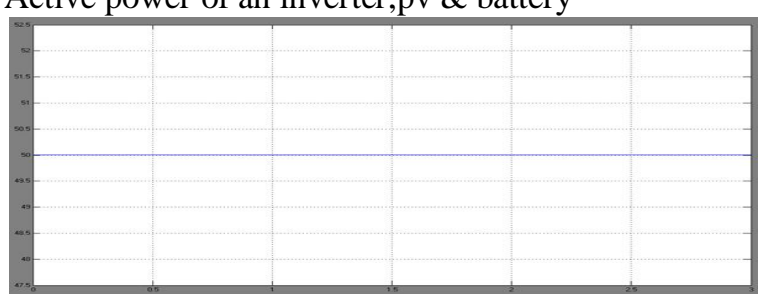

d) $\mathrm{SOC}$

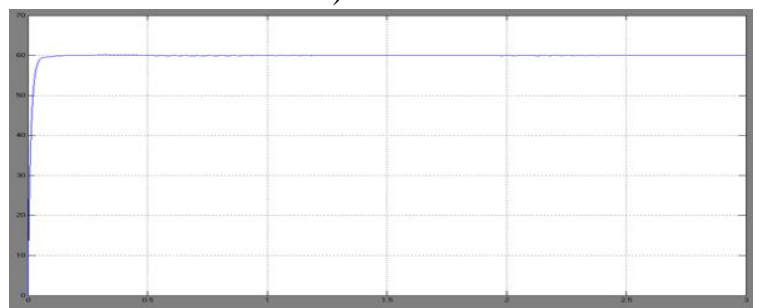

e) Frequency

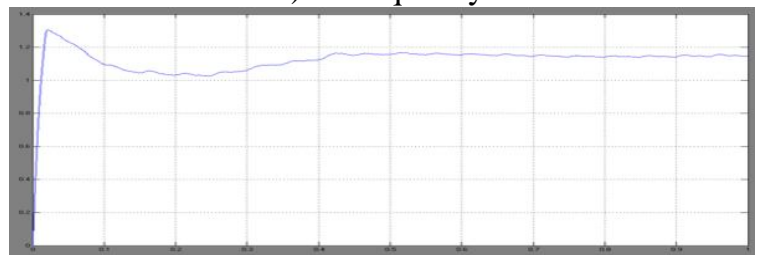

f) PCC Voltage $(\mathrm{pu})$

\section{CONCLUSION}

This project proposes and presents synchronized techniques of V-f supervision and P-Q supervision, respectively, for micro grids with $\mathrm{PV}$ generator and battery power storage. In the supervision techniques, the PV generator is operated at MPP, and battery storage acts as a buffer in order to provide and process lack or surplus power by using the charge/discharge cycle of battery power. The project contributes in representing the supervision techniques with resourceful coordination between inverter $\mathrm{V}-\mathrm{f}$ (or P-Q) supervision, MPPT supervision, and energy storage control.

\section{REFERENCES}

[1] R. H. Lasseter, "MicroGrids," in Proc. IEEE Power Engineering Society Winter Meeting, 2002, vol. 1, pp. 305308.

[2] S. Chowdhury, S. P. Chowdhury, and P. Crossley, "Microgrids and ActiveDistribution Networks," 2009, IET Renewable Energy Series 6.

[3] J. A. P. Lopes, C. L. Moreira, and A. G. Madureira, "Defining control strategies for MicroGrids islanded operation," IEEE Trans. Power Syst., vol. 21, pp. 916-924, 2006.

[4] B. Awad, J.Wu, and N. Jenkins, "Control of distributed generation," Electrotechn. Info. (2008), vol. 125/12, pp. 409414.

[5] J. C. Vasquez, J. M. Guerrero, E. Gregorio, P. Rodriguez, R. Teodorescu, and F. Blaabjerg, "Adaptive droop control applied to distributed generation inverters connected to the grid," in Proc. 2008 IEEE ISIE, pp. 2420-2425.

[6] H. Bevrani and S. Shokoohi, "An intelligent droop control for simultaneous voltage and frequency regulation in islanded microgrids," IEEE Trans. Smart Grid, vol. 4, no. 3, pp. 15051513, Sep. 2013.

[7] J. C. Vasquez, J. M. Guerrero, M. Savaghebi, and R. Teodorescu, "Modelling, analysis and design of stationary reference frame droop controlled parallel three-phase voltage source inverters," in Proc. 2011 IEEE 8th ICPE \& ECCE, pp. 272-279. 